\title{
A Solventless Method to Prepare Hematite using Thermal Decomposi- tion of Ferrocene
}

\author{
Ashis Bhattacharjee ${ }^{1 *}$, Amlan Rooj', Madhusudan Roy ${ }^{2}$ and Joachim Kusz ${ }^{3}$ \\ ${ }^{1}$ Department of Physics, Visva-Bharati University, Santiniketan, West Bengal, India \\ ${ }^{2}$ Surface Physics and Material Science Division, Saha Institute of Nuclear Physics, Kolkata, India \\ ${ }^{3}$ Institute of Physics, University of Silesia, Katowice, Poland
}

\begin{abstract}
Solventless solid state thermal reaction of ferrocene in presence of $\mathrm{Fe}(\mathrm{II})$ acetylacetonate is monitored by thermogravimetry. Though pure ferrocene suffers $100 \%$ mass loss on heating, the mixture of it with $\mathrm{Fe}(\mathrm{II})$ acetylacetonate gives rise to $\sim 20 \%$ decomposed material below $600 \mathrm{~K}$. Structure and morphology of the decomposed material are investigated by powder XRD and SEM techniques, respectively, while the magnetic property of the material is investigated by magnetization study as well as ${ }^{57} \mathrm{Fe}$ Mössbauer spectroscopy. The results observed from physical characterization studies establish unequivocally that the thermally decomposed material obtained by solventless synthesis is hematite. Thermal decomposition reaction leading to the formation of hematite particles using ferrocene takes place at comparatively lower temperatures. A process of solid state reaction brought about has been proposed.
\end{abstract}

\section{Keywords}

Thermal decomposition, Ferrocene, Hematite, XRD, SEM, SQUID, Mössbauer spectroscopy

\section{Introduction}

The transition metals and their oxides are of great interest in numerous scientific fields and applications, both as bulk materials and nano materials [1]. From the application point of view one of the most useful and interesting compounds is iron oxide. Over the last decade, iron oxide magnetic particles have been intensively studied [2-7] and owing to their exceptional physical properties various magnetic oxides have already been found to have important applications [8]. Physical properties of iron oxide magnetic particles greatly depend on the route of its synthesis and for that reason researchers have been using various approaches in order to change its properties in a controlled way for various application of current interest. Thermal decomposition of iron-bearing organic precursors is a very popular way to produce iron oxides of different phases $[3,6,9]$. Synthesis of magnetic iron oxides by thermal decomposition of ironorganic compounds has several advantages, such as a relatively low temperature of formation of magnetic oxides, a short reaction time, hazardless solventless solid state reaction and use of inexpensive iron-organic compounds. Thermal decomposition may take place in various steps, easily observed through thermogravimetry profile, and the reaction can be terminated at the end of any step. The properties of the decomposition product at the end of each step depend on the chemical nature of the precursor used, temperature and reaction atmosphere.

Organometallic compound - ferrocene $\left(\mathrm{C}_{5} \mathrm{H}_{5}\right)_{2} \mathrm{Fe}$ is an important precursor material for preparing iron oxide nanostructures through thermal decomposition [10-15]. Ferrocene is solid at room temperature and is reported to undergo $100 \%$ mass loss due to a single step thermal decomposition (sublimation) at $448 \mathrm{~K}$ [16]. Reaction kinetics of the solid state decomposition of ferrocene non-isothermal thermogravimetry has recently been studied using multiple heating rate programs [17]. Recently, we have reported a method for the preparation of single-phase nano-structured iron-oxide nanoparticles by solventless thermal decomposition of ferrocene [18]. We have established that the presence of solid guest molecules in the reaction atmosphere immensely influences the decomposition of ferrocene by affecting the reaction kinetics. To venture into this concept further, we have studied the thermal decomposition of ferrocene in the presence of guest molecule like iron(II) acetylacetonate to investigate the correlation among the thermal decomposition reaction kinetic parameters, morphology and physical characteristics of the reaction products and nature of the guest molecules. The decomposition kinetics was studied with thermogravimetry whereas the end product was characterized by various physical techniques.

*Corresponding author: Ashis Bhattacharjee, Department of Physics, Visva-Bharati University, Santiniketan, India, E-mail: ashis.bhattacharjee@visva-bharati.ac.in

Received: November 30, 2015: Accepted: March 04, 2016: Published: March 07, 2016

Copyright: ( 2016 Bhattacharjee A, et al. This is an open-access article distributed under the terms of the Creative Commons Attribution License, which permits unrestricted use, distribution, and reproduction in any medium, provided the original author and source are credited. 


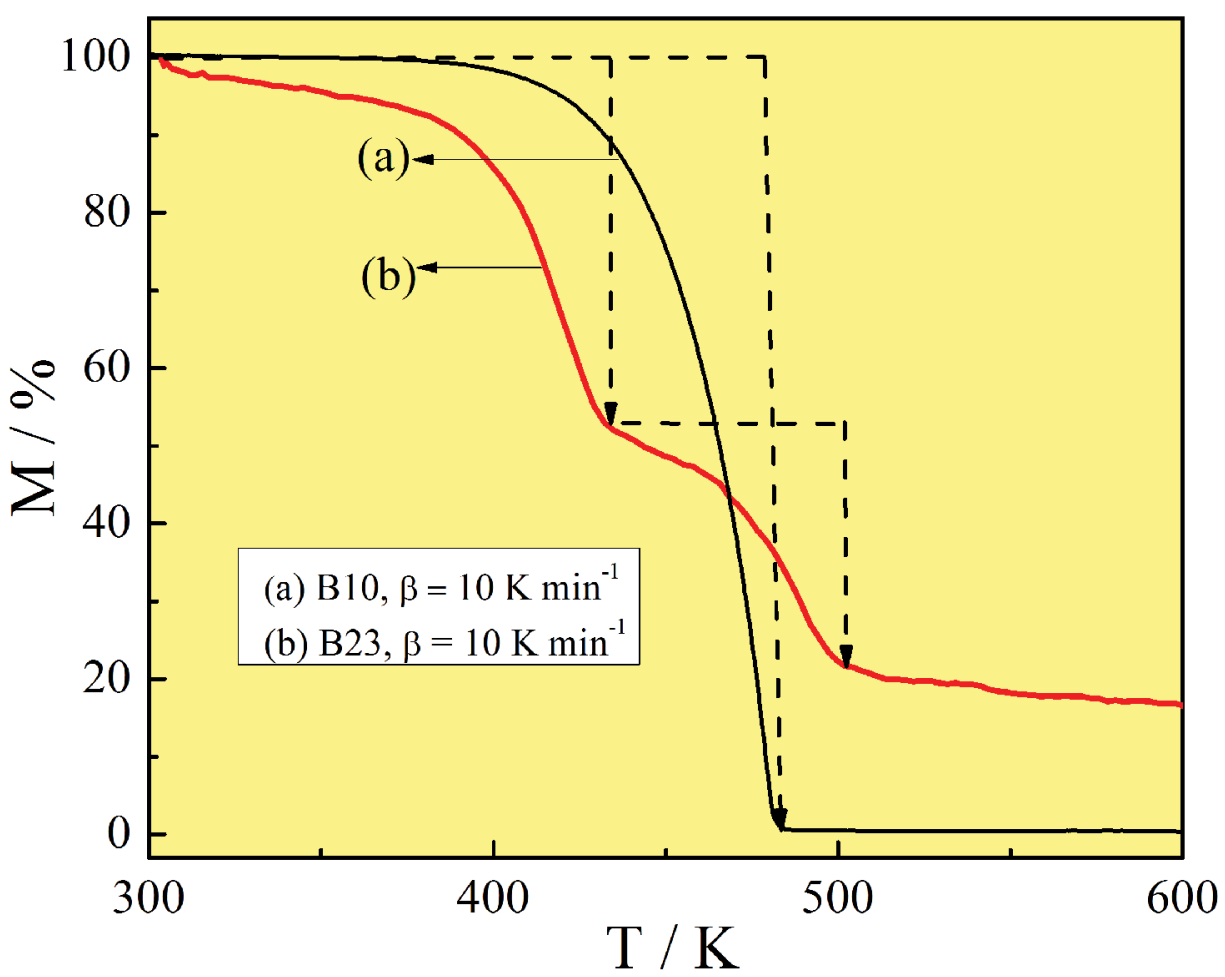

Figure 1: Thermogravimetry profiles obtained at $10 \mathrm{~K} /$ min heating rate. (a) B10 (ferrocene) and (b) B23 (40\% ferrocene $+60 \%$ Fe(II) acetylacetonate). Arrows are guide to the eyes. The dotted arrows indicate the steps of thermal decomposition.

In this paper, we report only the results obtained on the physical characterization of the thermally decomposed material utilizing powder XRD, SEM, SQUID magnetometry and ${ }^{57} \mathrm{Fe}$ Mössbauer spectroscopy. A solid state reaction pathway has been proposed.

\section{Materials and Methods}

The high quality polycrystalline ferrocene and $\mathrm{Fe}(\mathrm{II})$ acetylacetonate were purchased from SIGMA-ALDRICH and were used without further purifications. A solid mixture was prepared by grinding polycrystalline ferrocene and $\mathrm{Fe}(\mathrm{II})$ acetylacetonate together in 2:3 weight ratio using mortal-pestle. The samples for study were termed as B10 (ferrocene) and B23 (mixture of ferrocene and Fe(II) acetylacetonate in 2:3 weight ratio). Thermogravimetry measurements of the powdery samples of $\sim 5 \mathrm{mg}$ mass were carried out in 300 - 1000 $\mathrm{K}$ range at constant heating rate using a thermogravimetric analyzer of Netzsch, Germany (Model: STA 449C) in dry UHP nitrogen (99.99\%) nitrogen environment. The sample and reference crucibles used for measurements are made of alumina.

Certain amount of solid mixture (B23) was introduced into porcelain boat and then loaded into a furnace at $800^{\circ} \mathrm{C}$ for 8 hours for complete thermal decomposition. The thermally decomposed material (hereafter, B23d) was collected after cooling down to room temperature and was characterized by different physical techniques. $\mathrm{X}$-ray powder diffraction measurements were performed at room temperature using Seifert's diffractometer (XRD 3000 TT) equipped with monochromatic $\mathrm{Cu}-\mathrm{K}_{\alpha}$ radiation source and the Full Prof program was used for the purpose of quantitative phase analysis and for precise determination of unit cell parameters of crystalline phases. The scanning electron microscopy (SEM, model: FEI Quanta 200F) was employed to study the morphology of the decomposed material. Magnetization measurement was carried out by Quantum design's MPMS XL SQUID magnetometer. ${ }^{57} \mathrm{Fe}$ Mössbauer spectrum was recorded at room temperature using conventional nuclear spectroscopic instrumentation to study the magnetic structure of the decomposed material.

\section{Results and Discussion}

\section{Thermogravimetry}

Figure 1 represents the thermogravimetry (TG) profiles of B10 and $\mathrm{B} 23$ at $10 \mathrm{~K} \mathrm{~min}^{-1}$ heating rate in $300-600 \mathrm{~K}$ temperature regions. Ferrocene undergoes a one-step decomposition (sublimation) process as shown in plot (a), and it gets completed with $100 \%$ mass loss at $\sim 483 \mathrm{~K}$. Solid ferrocene thermally decomposes at $448 \mathrm{~K}$ (melting point) while its boiling point is $522 \mathrm{~K}$. In the temperature range from $\sim 870 \mathrm{~K}$ to $\sim 1420 \mathrm{~K}$ ferrocene further decomposes [19]. Leonhardt et al. [15] proposed that at temperatures above $\sim 770 \mathrm{~K}$, gaseous ferrocene decomposes spontaneously to form metallic iron, indicating that within this temperature range solid or liquid-like $\mathrm{Fe}$ particles and different kinds of hydrocarbons exist in the reaction medium. Thus, the presently observed thermal decomposition indicates that the sublimation of ferrocene to take place during solid state reaction and no further conversion to liquid or solid $\mathrm{Fe}$ has been observed as no increase in mass has been recorded in the TG profile. At this point it has to be noted that TG deals with a very small amount of sample mass. At higher temperatures when the further conversion of sublimated ferrocene to liquid or solid Fe takes place it is quite unlikely to be detected by the TG considering the converted sample mass.

The plot (b) shows the TG profile of B23 where the mass loss sets in $\sim 303 \mathrm{~K}$. The decomposition proceeds gradually through two linear steps where the decomposition becomes complete at $\sim 500 \mathrm{~K}$ with $\sim 20 \%$ residual mass. The observed TG profiles clearly indicate that the presence of $\mathrm{Fe}(\mathrm{II})$ acetylacetonate molecules not only modifies the decomposition of ferrocene, it increases the steps of decomposition processes as well as produces significant amount of solid residual mass. At this point it may be recalled that thermal decomposition of the solid mixtures of ferrocene and oxalic acid took place in three different steps and was completed below $460 \mathrm{~K}$ with $\sim 12 \%$ of solid residual hematite [18]. Thus, use of $\mathrm{Fe}(\mathrm{II})$ acetylacetonate though completes the thermal decomposition of ferrocene in two steps but at 


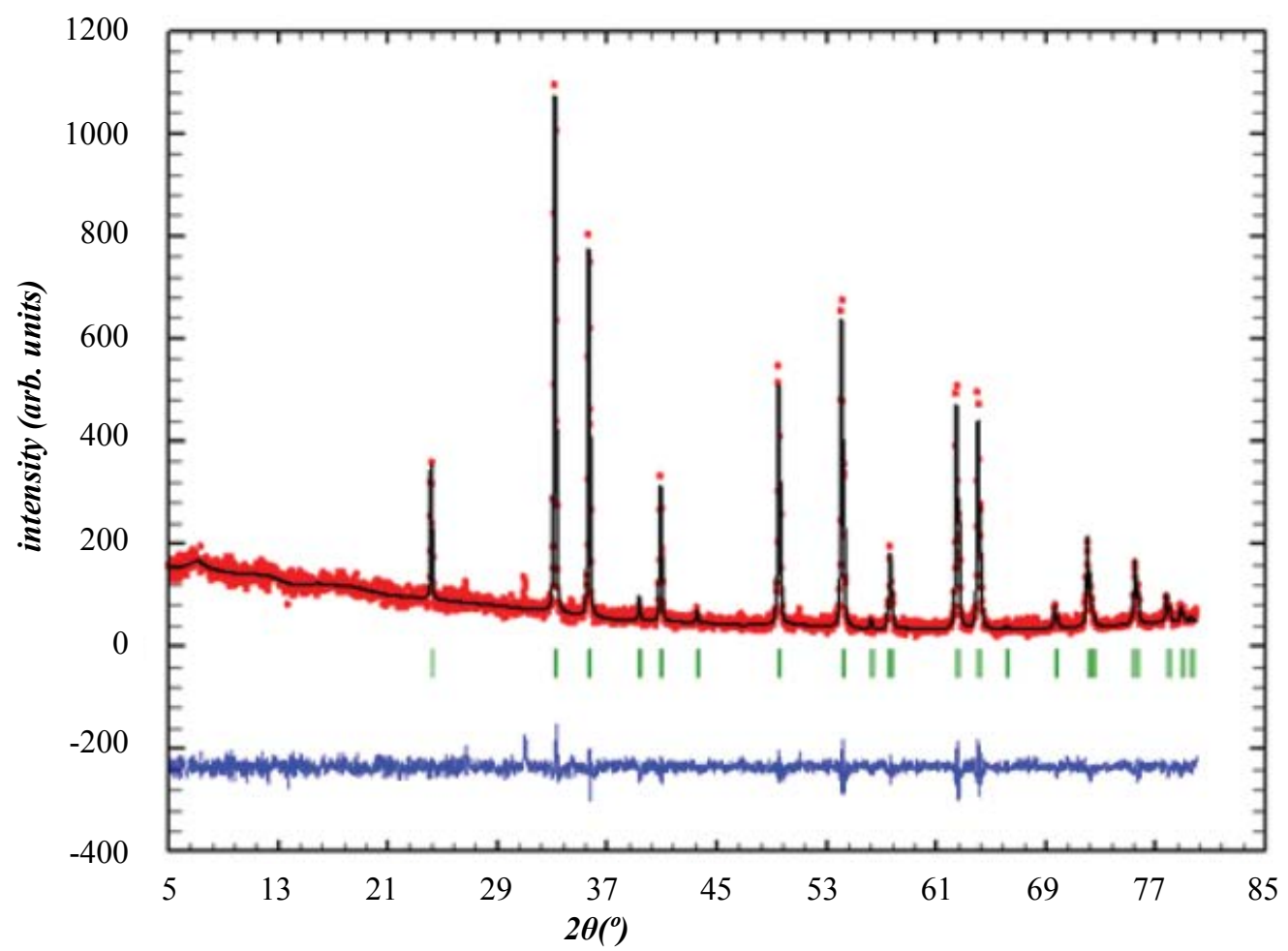

Figure 2: Powder XRD pattern of B23d at room temperature. Red points are the observed reflections; black line indicates the fit of the observed diffraction pattern; green lines mark the peak positions; blue lines indicate the residual pattern.

much lower temperatures in comparison to when oxalic acid is mixed with ferrocene.

\section{Powder X-ray diffraction and scanning electron microscopy}

The structure and composition of the decomposed material was investigated by the powder XRD method. X-ray powder diffraction (XRD) pattern of $\mathrm{B} 23 \mathrm{~d}$ obtained by using $\mathrm{Cu}-\mathrm{K}_{\alpha}$ line within the range $5^{\circ} \leq 2 \theta \leq 80^{\circ}$ at room temperature is shown in Figure 2. XRD pattern is analyzed to identify the components, unit cell parameters and mean crystallite size of the material. The estimated lattice parameters for B23d are $a=b=5.0322 \AA ; c=13.7378 \AA, \alpha=\beta=90.0^{\circ}, \gamma=120^{\circ}$. The XRD pattern clearly exhibits that all diffraction peaks/lines correspond to hematite (JCPDF no. 24-72 and 13-534). The mean crystallite size $D(=260 \mathrm{~nm})$ of B23d was estimated from the XRD peak broadening using the Scherer formula [20]. This result establishes that large-sized hematite particles can be synthesized on thermal decomposition of ferrocene in the presence of $\mathrm{Fe}(\mathrm{II})$ acetylacetonate.

Surface morphology and particle nature of B23d were observed by SEM (Figure 3). It indicates that the material formed on thermal decomposition is agglomerated particle in the form of tiny rod. There is a variation in the length $(250-350 \mathrm{~nm})$ and breadth $(100-150$ $\mathrm{nm}$ ) of the tiny rods as demonstrated by SEM. The observed mean size of B23d is close to the mean crystallite size estimated through the powder XRD study.

\section{Magnetization study}

Magnetic behavior of B23d was studied in 300-2-300 K range during three consecutive thermal cycling under $1 \mathrm{kOe}$ magnetic field. Figure 4 shows the temperature dependence of magnetization $(M)$ for B32d obtained in $300-100 \mathrm{~K}$ range. The $M(T)$ plots obtained during the $1^{\text {st }}$ cooling (1) down from room temperature shows a drop in magnetization values at $248 \mathrm{~K}$, which continues till $188 \mathrm{~K}$. Below this temperature the $M(T)$ values increase very slowly till $2 \mathrm{~K}$ following Curie law. While $1^{\text {st }}$ heating (2) above $2 \mathrm{~K}, M(T)$ plot retraces the same path as seen while cooling till $\sim 190 \mathrm{~K}$, but then rapidly increases up to $266 \mathrm{~K}$. Beyond $266 \mathrm{~K}, M(T)$ values again decrease slowly with increasing temperature up to $300 \mathrm{~K}$. On immediate start of the cooling below this temperature small increase appears in the $M(T)$ value start at $300 \mathrm{~K}$ as a result of which the $M(T)$ plots during the $2^{\text {nd }}$ cooling (3) and $2^{\text {nd }}$ heating (4) shift upwards almost in parallel. Another successive cooling-heating cycle - (5) and (6), results into similar changes in the magnetization as seen in $2^{\text {nd }}$ cooling-heating cycle. For B23d in the second and the third thermal cycling a thermal hysteresis loop of $12 \mathrm{~K}$ width in the $M(T)$ plots, associated with a sharp change in $M(T)$ values and centered around $\sim 242 \mathrm{~K}$, was observed.

From the XRD study, it is expected that B23d should be hematite. It is well known that a phase transition from a weakly ferromagnetic to an antiferromagnetic state on cooling below the Morin temperature ( $T_{M}=260 \mathrm{~K}$ ) occurs in hematite [21]. This is a magnetic phase transition in hematite where the antiferromagnetic ordering is reorganized from being aligned perpendicular to the c-axis to be aligned parallel to the c-axis below $T_{M}$. Morin transition is a yardstick for hematite materials [18]. Thus, the sharp change in $M(T)$ values and the occurrence of a thermal hysteresis, centered at $\sim 262 \mathrm{~K}$ and illustrated in Figure 4 , correspond to the Morin transition of the decomposed material. Thus, the presence of hematite in B23d material obtained on thermal decomposition of ferrocene in the presence of Fe(II) acetylacetonate is confirmed by the fingerprint - Morin transition - recorded through the magnetic measurements. Particle shape, size, crystallinity and surface condition affect the temperature of the Morin transition [22]. With consecutive thermal cycling, i.e., cooling (1) $\rightarrow$ heating $(2) \rightarrow$ cooling (3) $\rightarrow$ heating $(4) \rightarrow$ cooling $(5) \rightarrow$ heating $(6)$ there has been an increase in magnetization values leading to saturation as recorded for $\mathrm{B} 23 \mathrm{~d}$ at $300 \mathrm{~K}$. These irreversible changes observed in magnetization values with repeated thermal cycling may be interpreted in term of domain reorganization [23]. It is known that the thermal cycling through the Morin temperature changes the domain configuration of hematite. The saturation remanence of hematite is usually only partly recovered upon thermal cycling. The domain structure in its 


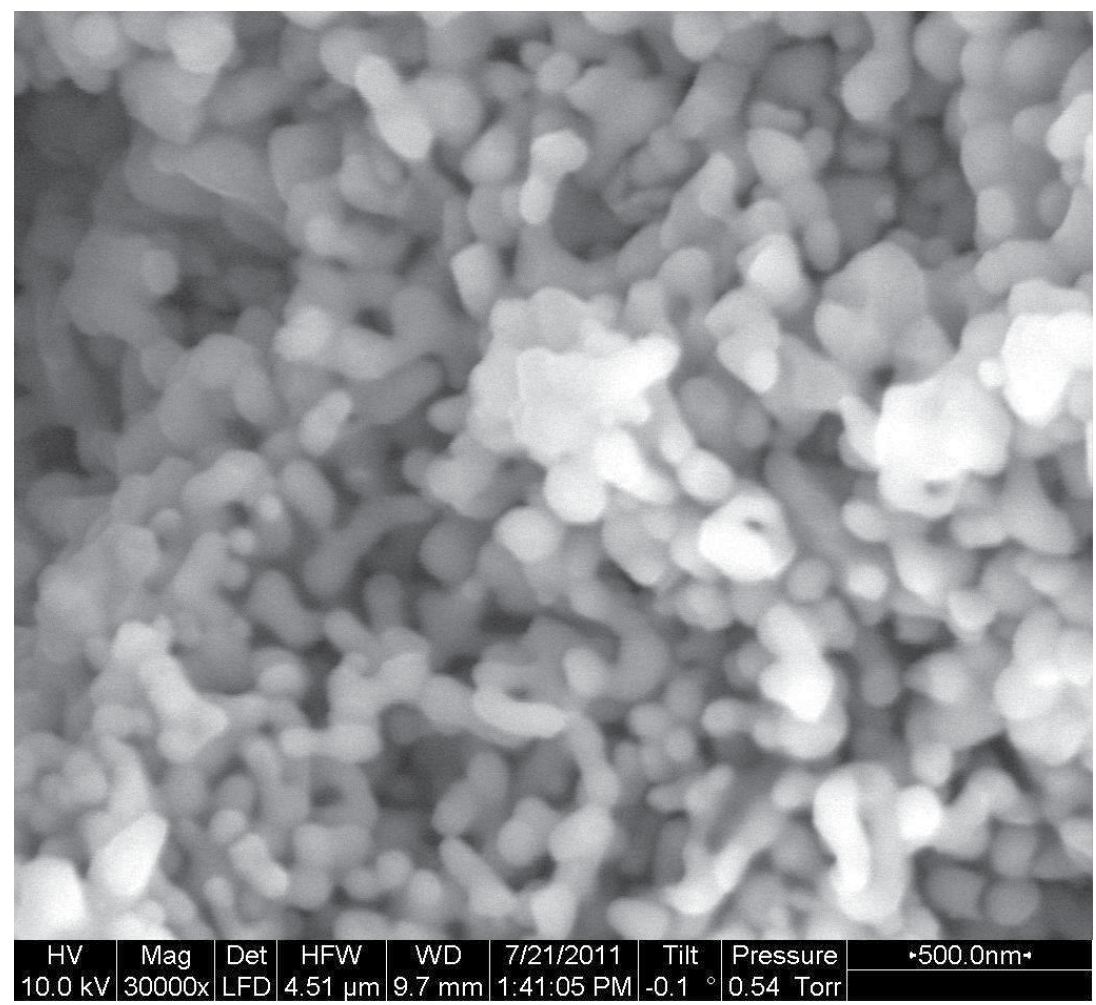

Figure 3: SEM micrograph of B23d.

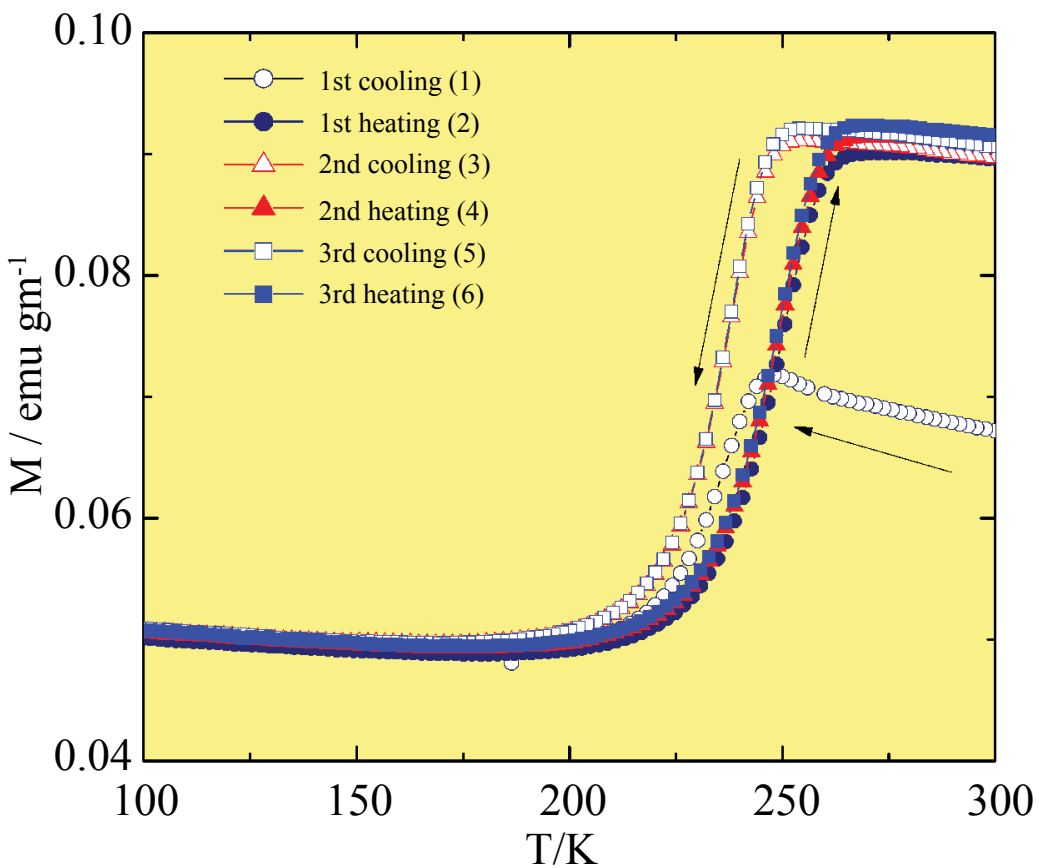

Figure 4: Temperature dependence of magnetization of B23d in three successive thermal cycles: cooling (1) $\rightarrow$ heating (2) $\rightarrow$ cooling (3) $\rightarrow$ heating (4) $\rightarrow$ cooling $(5) \rightarrow$ heating $(6)$. Arrows are guides to the eyes.

saturation remanent state shows that the most of the crystals lose their domain pattern on cooling [24,25]. Below the Morin temperature, a single-domain state is often observed, and if they are warmed to room temperature again, a new pattern is seen.

\section{Mössbauer spectroscopy}

${ }^{57} \mathrm{Fe}$ Mössbauer spectrum of B23d was recorded at $300 \mathrm{~K}$ (Figure 5). The spectra could be well fitted to two sextets (magnetic subspectra - S1 and S2) with the isomer shift with respect to $\alpha$-iron $(\delta)$, quadrupole splitting $\left(\Delta \mathrm{E}_{\mathrm{S}}\right)$, hyperfine field $\left(\mathrm{B}_{\mathrm{hf}}\right)$ and the line width as the adjustable parameters for the spectral fits. The presence of the sextets indicates the presence of long-range magnetic order in these materials at room temperature. The hyperfine parameters - isomer shift, quadrupole splitting, and hyperfine field were estimated from the best-fitted spectra. Population of the iron sites $(\eta)$ has also been estimated. The estimated hyperfine parameters are $0.37 \mathrm{~mm} \mathrm{~s}^{-1},-0.11$ 


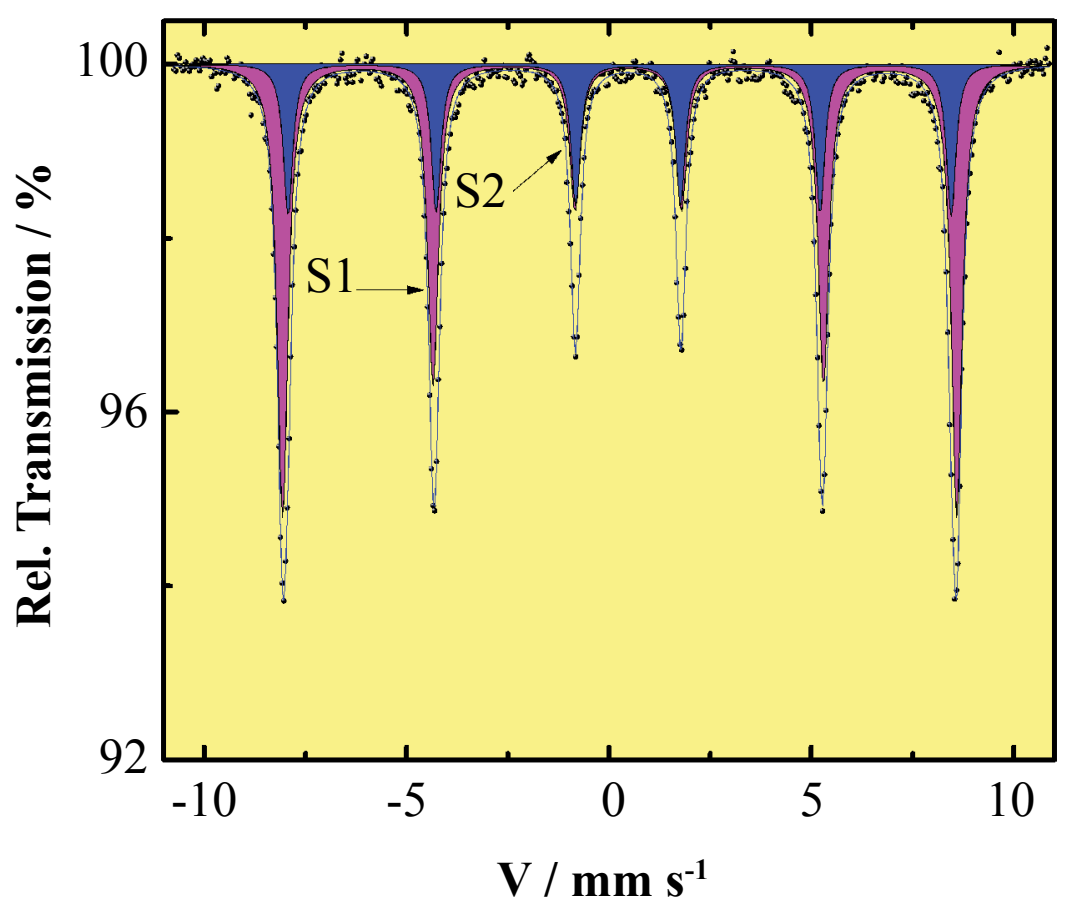

Figure 5: ${ }^{57} \mathrm{Fe}$ Mössbauer spectra of B23d obtained at room temperature.

$\mathrm{mm} \mathrm{s}^{-1}, 516 \mathrm{kOe}$ and $70 \%$ for sextet $\mathrm{S} 1$ and $0.37 \mathrm{~mm} \mathrm{~s}^{-1},-0.10 \mathrm{~mm} \mathrm{~s}^{-1}$, $508 \mathrm{kOe}$ and $30 \%$ for sextet S2. The observed hyperfine parameters for iron in B23d estimated at room temperature under zero applied magnetic field are in good agreement with those of hematite [26]. It is known that above the Morin temperature hematite is weakly ferromagnetic while below it is antiferromagnetic [21]. Thus, from Mössbauer spectroscopic study of B23d, it is undoubtedly established that the presently synthesized thermally decomposed material is pure hematite but appears with two slightly different magnetic phases, and is in complete agreement with the observations made from XRD and magnetic studies. Occurrence of six-line magnetic subspectra and no evidence of superparamagnetic relaxation in the room temperature Mössbauer spectra are in agreement with the comparatively large size of the hematite particle determined from XRD analysis.

\section{Solid state reaction: A possibility}

Pol et al. [27] carried out decomposition of Fe(II)acetylacetonate up to $973 \mathrm{~K}$ under inert atmosphere and observed three steps of decomposition with major mass loss ( 66\%) below $573 \mathrm{~K}$ and did not receive any crystalline products below $873 \mathrm{~K}$. They observed that the reactant possesses $\mathrm{a}+2$ oxidation state, while the product has an oxidation state of 2.66. This means that part of the original $\mathrm{Fe}^{2+}$ was oxidized. This indicated the formation of $\mathrm{Fe}_{3} \mathrm{O}_{4}$ occurs first followed by the formation of carbon sheets. On decomposition of Fe(II)acetylacetonate, $\mathrm{C}_{2} \mathrm{H}_{2}, \mathrm{C}_{3} \mathrm{H}_{6}, \mathrm{CO}_{2}, \mathrm{C}$, and $\mathrm{CH}_{3} \mathrm{COCH}_{3}$ escape, mostly below $573 \mathrm{~K}$, as confirmed by mass spectroscopy. Once again, $4 \%$ at $623 \mathrm{~K}$ and $7.7 \%$ at $\sim 923 \mathrm{~K}$ weight losses were observed in the mass spectrum as $\mathrm{C}$. The detected $\mathrm{C}$ might have originated from the dissociation of hydrocarbons under the electron bombardment inside the mass spectrometer and not from the gaseous carbon. On the other hand, in the light of suggestions of Dyagileva et al. [19] and Leonhardt et al. [15] one can write that at high temperatures, gaseous ferrocene decomposes spontaneously to form metallic iron according to the following reaction

$$
\left(\mathrm{C}_{5} \mathrm{H}_{5}\right)_{2} \mathrm{Fe} \rightarrow \mathrm{Fe}+\mathrm{H}_{2}+\mathrm{CH}_{4}+\mathrm{C}_{5} \mathrm{H}_{6}+\cdots--\cdot
$$

In the present case, decomposition of the mixture of ferrocene and $\mathrm{Fe}(\mathrm{II})$ acetylacetonate proceeded through two steps and finally resulted into the formation of $\sim 20 \%$ end-product, and the decomposed material is of pure hematite phase in complete agreement with the observations made from XRD, magnetic and Mössbauer studies. As hematite is formed due to thermal decomposition of ferrocene and $\mathrm{Fe}(\mathrm{II})$ acetylacetonate mixtures, the possible reaction may be assumed through the following equations:

$$
\begin{aligned}
& \text { 1. }\left(\mathrm{C}_{5} \mathrm{H}_{5}\right)_{2} \mathrm{Fe} \rightarrow \mathrm{Fe}+\mathrm{H}_{2}(\mathrm{~g})+\mathrm{CH}_{4}(\mathrm{~g})+\mathrm{C}_{5} \mathrm{H}_{6}(\mathrm{~g})+\cdots . . \\
& \text { 2. }\left[\mathrm{C}_{10} \mathrm{H}_{14} \mathrm{FeO}_{4}\right] \rightarrow \mathrm{Fe}_{2} \mathrm{O}_{3}+\mathrm{CO}_{2}(\mathrm{~g})+3 \mathrm{CO}(\mathrm{g})+\mathrm{C}_{2} \mathrm{H}_{2}(\mathrm{~g})+\mathrm{H}_{2}(\mathrm{~g}) \\
& \text { 3. }\left[\left(\mathrm{C}_{5} \mathrm{H}_{5}\right)_{2} \mathrm{Fe}\right]+\mathrm{C}_{10} \mathrm{H}_{14} \mathrm{FeO}_{4} \rightarrow \mathrm{Fe}_{2} \mathrm{O}_{3}(\mathrm{~g})+\mathrm{CO}_{2}(\mathrm{~g})+\mathrm{CO}(\mathrm{g})+
\end{aligned}
$$
$\mathrm{H}_{2}(\mathrm{~g})+\ldots \ldots \ldots$.

It is interesting to note that pure Fe(II) acetylacetonate on thermal decomposition produces magnetite whereas that when takes place in presence of ferrocene gives rise to hematite.

\section{Conclusion}

Solid state thermal decomposition of a mixture of two molecular iron-bearing precursors - ferrocene and $\mathrm{Fe}(\mathrm{II})$ acetylacetonate has been studied. The decomposition is a single-step process for ferrocene, whereas a two-step one for ferrocene mixed with $\mathrm{Fe}(\mathrm{II})$ acetylacetonate in 2:3 weight ratio in the working range of temperature. Ferrocene when heated alone above $\sim 770 \mathrm{~K}$ does not produce any solid traceable solid residual material detectable in the TG profile, but when it is heated together with $\mathrm{Fe}(\mathrm{II})$ acetylacetonate, solid hematite product is formed at $\sim 490 \mathrm{~K}$. Decomposed material contains granular hematite rod like particles of length and breadth lying between $250-350 \mathrm{~nm}$ and $100-150 \mathrm{~nm}$, respectively. Earlier it has been reported that thermal decomposition of ferrocene in presence of oxalic acid leads to the formation of particles of $\sim 40 \mathrm{~nm}$ [18]. Thus, comparing with the present results with those reported in ref. [18], it may be conjectured that utilizing ferrocene as the primary precursor, iron oxide (hematite) particles of various size/ morphology can be obtained based on the nature of guest precursors through solventless method. In this light, our search aims at suitable guest molecules and reaction conditions for the solventless synthesis of iron oxide particles of varying size/morphology with no interfering solid by-products utilizing ferrocene as the primary precursor is 
continuing. Reaction kinetics parameters should be the key factors for controlling the size, shape and yield of the iron oxide particles thus formed.

\section{Acknowledgement}

Financial supports for the thermogravimetry analyzer (STA 449 F3 Jupiter) from the Department of Science and Technology (DST), Govt. of India through FIST-2010 (to the Department of Physics) is gratefully acknowledged.

\section{References}

1. Reithmaier JP, Petkov P, Kulisch W, Popov C (2008) Nanostructured Materials for Advanced Technological Applications. NATO Science for Peace and Security Series B: Physics and Biophysics.

2. Lv B, Xu Y, Wu D, Sun $Y$ (2008) Preparation and properties of magnetic iron oxide nanotubes. Particuology 6: 334-339.

3. Zhang YC, Tang JY, Hu XY (2008) Controllable synthesis and magnetic properties of pure hematite and maghemite nanocrystals from a molecular precursor. J Alloy Compd 462: 24-28.

4. Bhalerao GM, Sinha AK, Srivastava H, Srivastava AK (2009) Synthesis and studies of growth kinetics of monodispersed iron oxide nanoparticles using ferrocene as novel precursor. Appl Phys A 95: 373

5. Kahn ML, Glaria A, Pages C, Monge M, Macary LS, et al. (2009) Organometallic chemistry: an alternative approach towards metal oxide nanoparticles. J Mater Chem 19: 4044-4060.

6. Bhattacharjee A, Roy D, Roy M, Chakraborty S, De A, et al. (2010) Rod-like ferrites obtained through thermal degradation of a molecular ferrimagnet. $J$ Alloy Compd 503: 449-453.

7. Pol VG, Daemen LL, Vogel S, Chertkov G (2010) Solvent-free fabrication of ferromagnetic $\mathrm{Fe}_{3} \mathrm{O}_{4}$ octahedra. Ind Eng Chem Res 49: 920-924.

8. Fierro JLG, Fierro LLG (2006) Metal Oxides: Chemistry and Applications. Taylor \& Francis, CRC, Boca Raton.

9. Amara D, Grinblat J, Margel S (2012) Solventless thermal decomposition of ferrocene as a new approach for one-step synthesis of magnetite nanocubes and nanospheres. J Mater Chem 22: 2188-2195.

10. Koprinarov N, Konstantinova M, Marinov M (2010) Ferromagnetic nanomaterials obtained by thermal decomposition of ferrocene. Solid State Phenom 159: 105-108.

11. Elihn K, Landstörm L, Alm O, Boman M, Heszler P (2007) Size and structure of nanoparticles formed via ultraviolet photolysis of ferrocene. J Appl Phys 101: 034311.
12. Sajitha EP, Prasad V, Subramanyam SV, Mishra AK, Sarkar S, et al. (2007) Structural, magnetic and Mössbauer studies of iron inclusions in a carbon matrix. J Magn Magn Mater 313: 329-336.

13. Rooth $M$, Johansson $A$, Boman $M$, Hårsta $A$, Jaan Aarik, et al. (2008) Atomic layer deposition of iron oxide thin films and nanotubes using ferrocene and oxygen as precursors. Chem Vap Deposition 14: 67-70.

14. Barreiro A, Hampel S, Rümmeli MH, Kramberger CK, Grüneis A, et al. (2006) Thermal decomposition of ferrocene as a method for production of singlewalled carbon nanotubes without additional carbon sources. J Phys Chem B 110: 20973-20977.

15. Leonhardt A, Hampel S, Muller C, Mönch I, Koseva R, et al. (2006) Synthesis, properties, and applications of ferromagnetic-filled carbon nanotubes. Chem Vap Deposition 12: 380-387.

16. de Souza AC, Pires ATN, Soldi V (2002) Thermal stability of ferrocene derivatives and ferrocene-containing polyamides. J Therm Anal Cal 70: 405-414.

17. Bhattacharjee A, Rooj A, Roy D, Roy M (2014) Thermal decomposition study of ferrocene $\left[\left(\mathrm{C}_{5} \mathrm{H}_{5}\right)_{2} \mathrm{Fe}\right]$. J Exp Phys.

18. Bhattacharjee A, Rooj A, Roy M, Kusz J, Gütlich P (2013) Solventless synthesis of hematite nanoparticles using ferrocene. J Mater Sci 48: 2961-2968.

19. Dyagileva LM, Marin VP, Tsyganova El, Razuvaev GA (1979) Reactivity of the first transition row metallocenes in thermal decomposition reaction. J Organomet Chem 175: 63-72.

20. Cullity BD (1956) Elements of X-ray diffraction. Addison-Wesley.

21. Morin FJ (1950) Magnetic susceptibility of $\alpha-\mathrm{Fe}_{2} \mathrm{O}_{3}$ and $\alpha-\mathrm{Fe}_{2} \mathrm{O}_{3}$ with added titanium. Phys Rev 78: 819.

22. Zysler RD, Fiorani D, Testa AM, Godinho M, Agostinelli E, et al. (2004) Size effects in the spin-flop transition of hematite nanoparticles. J Magn Magn Mater 272: 1575 .

23. De Boer CB, Mullender TAT, Dekker MJ (2001) Low-temperature behaviour of haematite: susceptibility and magnetization increase on cycling through the Morin transition. Geophys J Int 146: 201-206.

24. Eaton JA, Morrish AH (1969) Magnetic domains in hematite at and above the Morin transition. J Appl Phys 40: 3180.

25. Morrish AH (1994) Canted Antiferromagnetism: Hematite. World Scientific, London.

26. Lyubutin IS, Lin CR, Korzhetskiy YV, Dmitrieva TV, Chiang RK (2009) Mössbauer spectroscopy and magnetic properties of hematite/magnetite nanocomposites. J Appl Phys 106: 034311.

27. Pol SV, Pol VG, Gedanken A, Sung MG, Asai S (2008) Effects of a 10T external magnetic field on the thermal decomposition of $\mathrm{Fe}, \mathrm{Ni}$, and Co acetyl acetonates. Langmuir 24: 7532-7537. 